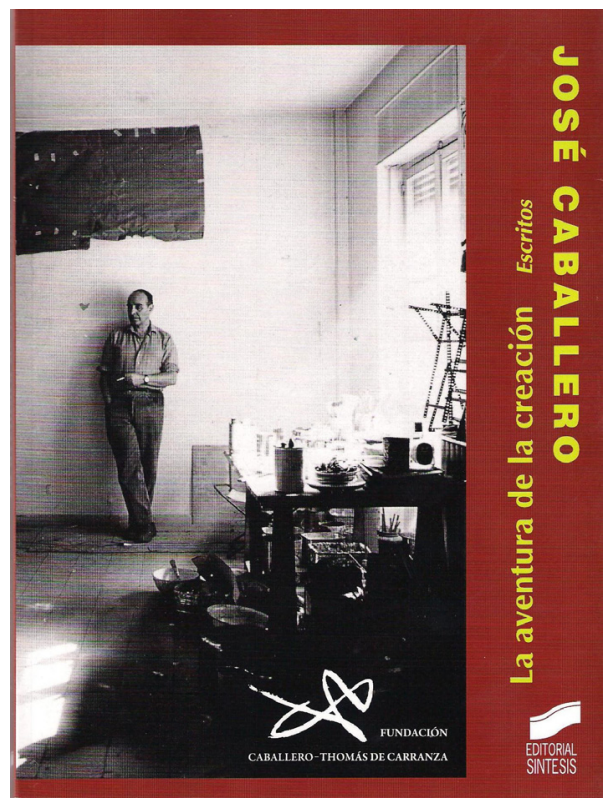

\title{
La aventura de la creación: Escritos.
}

José Caballero (1915-1991)

Editorial Síntesis

Madrid, 2014

ISBN 978-84-9958-824-7

La Editorial Síntesis, en colaboración con la Fundación Caballero-Thomas de Carranza, publica La aventura de la creación. Escritos de José Caballero, colección El Espíritu y la letra, no 19 de su catálogo.

Un volumen de 209 páginas, numerosas ilustraciones de obras del autor y fotografías en blanco y negro. María Fernanda Thomas de Carranza, Presidenta de la Fundación Caballero-Thomas de Carranza, explica en su presentación cómo conoció al pintor, como fue su convivencia y qué criterios ha seguido en la selección de textos publicados, porque hay fragmentos de cuadernos personales, de entrevistas, semblanzas, artículos de periódico y revistas.

Tras un breve prólogo de Francisco Calvo Serraller, se abre paso la escritura de José Caballero (1915-1991), cuya vida atravesó el siglo XX casi al completo. Se inicia el cuerpo de textos con el apartado "Evolución", en el que el pintor sintetiza sus diversas etapas o épocas creativas. A continuación, la verdadera materia de La aventura de la creación, con dos partes diferenciadas: la primera, referida a la propia creación con distintas entradas sobre su manera de entender el arte y el pensamiento y la novedad de varios poemas, tanto éditos como inéditos. Para terminar con las "Semblanzas" sobre creadores de su entorno: Daniel Vázquez Díaz, su maestro; Pablo Neruda, Picasso, Federico 
García Lorca, Alberto, Luis Buñuel, Miguel Hernández, Alberti, Bergamín, Juana Mordó, Caballero Bonald, Moreno Galván, Carlos Pascual de Lara...

Aunque hay reflexiones sobre el arte y su historia, sobre Goya y Velázquez, Juan Gris o Torres García, el contenido puede considerarse como una visión autobiográfica, porque habla de su vida, sus referentes, su contacto con el mundo del arte y sus estados de ánimo, sus impulsos ante la tela en blanco y su repulsa a la repetición. Lo mejor que tiene el libro es que transparenta la sencillez de José Caballero; se palpa la latencia de su claridad, su lenguaje esencial, fluido, fácil para la lectura. Entre los textos de algunos colegas actuales y esta prosa límpida, diáfana, hay una distancia como de la noche al día.

Hay que confiar en el buen criterio de $\mathrm{M}^{\mathrm{a}}$ Fernanda Thomas de Carranza, su musa y su compañera, porque al ser una selección de los escritos -hay mucho más de lo publicado- se impone una mirada personal de quien antologa, que podría no coincidir con la de otros especialistas que hubieran hecho la edición. A su favor está el conocer de primera mano las circunstancias en las que se produjeron esos escritos y las impresiones de Caballero. Pepe Caballero, siendo el más joven del grupo, fue un epígono de la generación del 27, tras la guerra se convirtió en un exiliado interior, con verdaderos problemas para ubicarse en la sociedad de la posguerra. En el apartado "Evolución", el mismo pintor registra su andadura y sus etapas, volcándose en la materia, los círculos y las signografías.

Junto a José Pérez-Guerra fui testigo de sus exposiciones y actos en los últimos 15 años de su vida y por ello conozco alguno de los textos, que me ha emocionado volver a leer, como la defensa de don Jaime del Valle-Inclán, hoy absolutamente olvidado. La aventura de la creación es una magnífica oportunidad para recordar la vida honesta de un maestro o para conocer la andadura existencial de un autor de culto de nuestra historia del arte.

TOMÁS PAREDES ROMERO

Presidente Asociación Española de Críticos de Arte

AECA/AICA Spain 